\title{
Pengukuran Taksiran Berat Janin Saat Bayi Baru Lahir pada Primipara Lebih Akurat Menggunakan Metode Dare's dan pada Multipara Lebih Akurat Menggunakan Metode Johnson Syahrir
}

\author{
Measurement of Fetal Weight Estimation at Newborns in Primipara is More Accurate Using \\ Dare's Method and in Multipara is More Accurate Using Johnson Syahrir's Method
}

\author{
Martini Fairus ${ }^{1, \bigotimes}$, Martini Martini ${ }^{1}$, Riyanto Riyanto ${ }^{1}$ \\ ${ }^{1}$ Jurusan Kebidanan, Politeknik Kesehatan Tanjung Karang, Indonesia \\ ${ }^{\bowtie}$ Corresponding author: fairus.toha@gmail.com
}

\begin{abstract}
Kata kunci:
Akurasi taksiran berat janin,

metode Dar's primipara, metode Johnson Syahrir multipara.
\end{abstract}

\begin{abstract}
Abstrak
Latar belakang: Salah satu cara pemantauan pertumbuhan dan kesejahteraan janin melalui pengukuran taksiran berat janin untuk mencegah gangguan pertumbuhan janin. Tujuan: Penelitian bertujuan mengetahui perbandingan akurasi beberapa metode pengukuran taksiran berat janin pada primipara dan multipara terhadap berat badan bayi baru lahir. Metode: Penelitian ini menggunakan rancangan deskriptif komparatif dilaksanakan di Pusat kesehatan masyarakat rawat inap wilayah Lampung Tengah. Sampel penelitian berjumlah $104 \mathrm{ibu}$ bersalin primipara dan $104 \mathrm{ibu}$ bersalin multipara yang diambil dengan teknik consecutive sampling Analsis bivariat menggunakan uji korelasi. Hasil: Hasil penelitian menunjukkan taksiran berat janin menggunakan 5 metode pengukuran pada primipara memperoleh keeratan korelasi metode Dare's korelasi 64\%, metode Johnson Tohsach korelasi $64,1 \%$, metode Niswander korelasi $64,1 \%$, dan metode sederhana korelasi 60,4\%, dan metode Johnson Syahrir korelasi 52,2\%. Sedangkan, pada multipara memperoleh hasil metode Johnson Tohsach korelasi 78,2\%, metode Niswander 76,5\%, metode Dare's korelasi $71,1 \%$, dan metode sederhana 58,0\%. Simpulan: Pengukuran taksiran berat janin terhadap berat bayi baru lahir pada primipara yang paling akurasi adalah metode Dare's, sedangkan pada multipara adalah metode Johnson Syahrir. Hendaknya tenaga kesehatan melakukan pengukuran taksiran berat janin pada primipara menggunakan metode Dare's dan pada multipara menggunakan metode Johnson Syahrir.
\end{abstract}

\footnotetext{
Keyword:

Accuracy of estimated fetal weight, the Dar's primipara method, the Johnson Syahrir multipara method.
}

\begin{abstract}
s
Background: One way to monitor fetal growth and well-being is by measuring fetal weight estimates to prevent fetal growth disorders. Purpose: The aim of this study is to compare the accuracy of methods of measuring fetal weight estimation in primiparous and multiparous for newborns' weight. Methods: This study used a comparative descriptive design carried out at an inpatient community health center in the Central Lampung region. The research sample consisted of 104 primiparous women and 104 multiparous women who were taken by bivariate consecutive sampling technique using correlation test. Results: The results showed the estimated fetal weight using 5 measurement methods in primipara obtained a correlation of Dare's correlation of $64 \%$, Johnson Tohsach's correlation of $64.1 \%$, Niswander's correlation of $64.1 \%$, and simple method of correlation of $60.4 \%$, and Johnson Syahrir method correlation of 52.2\%. Whereas, the multipara obtained the results of the Johnson Tohsach method with a correlation of $78.2 \%$, the Niswander method $76.5 \%$, the Dare's correlation method $71.1 \%$, and the simple method $58.0 \%$. Conclusion: The most accurate measurement of fetal weight estimation of newborn weight in primipara is the Dare's method, whereas in multipara is the Johnson Syahrir method. Health professionals should measure fetal weight estimates in primipara using the Dare's method and in multipara using the Johnson Syahrir method.
\end{abstract}




\section{Pendahuluan}

Berat janin salah satu indikator kesejahteraan pertumbuhan janin dalam rahim. Oleh karena itu pengukuran berat janin merupakan langkah penting yang harus dilakukan oleh seorang bidan ketika memberikan asuhan antenatal. Melalui pengukuran estimasi berat janin pertumbuhan dan kesejahteraan janin dapat diketahui (Iriyanti, dkk. 2014).

Berat janin kurang merupakan salah satu penyebab kematian janin dalam rahim atau intra uterine fetal death (IUFD). Hasil studi Froen (2004), menunjukkan bahwa dari 52\% kejadian IUFD disebabkan oleh pertumbuhan janin kurang selama dalam kandungan (Froen, 2004., dalam (Iriyanti, dkk. 2014). Di kota Metro berdasarkan hasil penelitian yang dilakukan terhadap beberapa rumah sakit di kota Metro pada tahun 2014 terdapat 69 kasus kematian janin dalam rahim (Fairus \& Widiyanti, 2005)

Gangguan pertumbuhan janin dalam rahim dapat dicegah melalui pemantauan pertumbuhan dan kesejahteraan janin saat ante natal care. Salah satu cara pemantauan pertumbuhan dan kesejahteraan janin adalah melalui pengukuran taksiran berat janin. Melalui pengukuran tersebut dapat diketahui apakah pertumbuhan janin sesuai dengan usia kehamilan, lebih besar dari usia kehamilan atau janin mengalami hambatan pertumbuhan. Mengetahui kondisi pertumbuhan janin akan mengarahkan bidan untuk melakukan tindakan selanjutnya secara cepat dan tepat, untuk kesejahteraan janin (Varney, Kriebs, \& Gegor, 2008).

Pengukuran pertumbuhan janin dalam rahim, sangat tepat jika menggunakan peralatan canggih seperti ultrasonografi. Akan tetapi, pada negara berkembang seperti di Indonesia, persalinan masih banyak terjadi di rumah atau di bidan praktik mandiri, yang pengukuran perkiraan berat janin belum mempergunakan peralatan canggih. Selain fasilitas tidak tersedia, juga memerlukan biaya mahal. Karena itu perlu dikembangkan teknik pengukuran yang sederhana namum unggul dan dapat diandalkan.

Terdapat beberapa metode pengukuran berat janin dalam rahim. Masing-masing metode memiliki rumus perhitungan yang berbeda-beda. Metode yang banyak digunakan saat ini adalah pengukuran menggunakan metode Johnson Tohsach, metode modifikasi rumus Johnson menurut Syahrir, metode Niswander, metode TFU sederhana dan metode Dare,s. Pelaksanaan dilapangan, metode Johnson Tohsach lebih banyak digunakan untuk menghitung taksiran berat janin, baik pada primipara maupun multipara.

Penelitian ini bertujuan membandingkan akurasi kelima metode pengukuran taksiran berat janin tersebut pada primipara dan multipara. Sehingga, dapat diketahui metode yang paling akurat dalam menaksir berat janin pada primipara dan diketahui metode yang paling akurat dalam menaksir berat janin pada multipara. Primipara adalah seseorang yang baru pertama bersalin, sedangkan multipara adalah seseorang yang sudah melahirkan dua kali atau lebih. Wanita yang sudah pernah melahirkan, mengalami pemisahan otot pada dinding perutnya atau diastasis rectus akibat regangan perut selama kehamilan. Pemisahan otot perut menyebabkan otot menjadi kendur dan tonus otot perut menjadi kurang baik. Wanita yang melahirkan pertama memiliki tonus otot yang lebih baik karena belum pernah mengalami peregangan dinding perut sebelumnya. Perbedaan tonus otot ini dimungkinkan menyebabkan adanya perbedaan akurasi terhadap suatu metode pengukuran taksiran berat janin. Oleh karena itu, penelitian ini bertujuan untuk mengidentifikasi akurasi beberapa metode pengukuran taksiran berat janin pada primipara dan multipara terhadap berat badan bayi baru lahir.

\section{Metode Penelitian}

Jenis penelitian ini kuantitatif. Bentuk hubungan variabel yang digunakan adalah perbedaan (komparatif) atau deskriptif komparatif dengan pendekatan kohort retrospektif. Rancangan penelitian digunakan untuk menggambarkan perbedaan akurasi metode pengukuran taksiran berat janin meliputi 
metode Johnson Tohsach, modifikasi metode Johnson Syahrir, metode Niswander, metode TFU sederhana, metode Dare's pada primipara dan multipara terhadap berat bayi setelah dilahirkan. Penelitian dilakukan di Puskesmas Rawat Inap di wilayah Lampung Tengah.

Populasi penelitian seluruh ibu bersalin inpartu kala I yang datang ke di Puskesmas pada bulan Juni - Nopember 2016. Estimasi besar sampel menggunakan perhitungan besar sampel untuk penelitian diagnostik (Sopiyudin, 2009) memperoleh jumlah sampel minimal 95 orang ibu bersalin, Untuk menghindari adanya ketidaktepatan pemeriksaan sampel di tambah 10\% menjadi 104 sampel, sehingga masing-masing 52 primipara dan 52 multipara. Teknik pengambilan sampel dengan nonprobability sampling, dengan teknik consecutive sampling yang memenuhi kriteria inklusi. Kriteria inklusi penelitian meliputi, ibu bersalin dengan usia kehamilan aterm atau yaitu 37 minggu sampai 42 minggu inpartu kala I, presentasi kepala, dan bersedia menjadi subyek penelitian. Kriteria eksklusi yaitu bersalin yang mengalami mengalami komplikasi kehamilan dan persalinan.

Pengumpulan data menggunakan metode wawancara untuk menmperoleh data primipara dan multipara dengan instrumen kuesioner bentuk check list dan observasi hasil penimbangan bayi baru lahir dengan menggunakan alat meteran pita dan formulir check list dengan hasil ukur tinggi fundus uteri dalam $\mathrm{cm}$ dan taksiran berat janin dalam gram dari metode-metode taksiran berat janin terhadap bayi baru lahir. Variabel penelitian yang diukur meliputi, berat badan bayi baru lahir dan Metode pengukuran taksiran berat janin, yaitu, metode Johnson Tohsach, modifikasi metode Johnson Syahrir, metode Niswander, metode TFU sederhana dan metode Dare's. Data hasil penelitian dianalisis secara univariat untuk menggambarkan secara deskriptif frekuensi distribusi denngan tabel dan analisis bivariat menggunakan uji parametrik, yaitu uji korelasi untuk menentukan perbedaan hasil pengukuran pengukuran taksiran berat janin dari masing-masing metode pengukuran.

\section{Hasil}

\section{Karakteristik responden}

Tabel 1 memberikan gambaran karaktersitik responden primipara berdasarkan rata-rata BB sebelum hamil adalah 51,2 kg, berdasarkan BB setelah hamil 60,6 kg, usia rata-rata 26,7 tahun, Tinggi Fundus Uteri rata-rata $31,2 \mathrm{~cm}$ dan lingkar perut rata-rata $94,2 \mathrm{~cm}$ dan rata-rata BB bayi lahir $3157 \mathrm{gram}$. Sedangkan, pada tabel 2 menunjukkan karaktersitik responden multipara para berdasarkan rata-rata BB sebelum hamil adalah 50,3 kg, berdasarkan BB setelah hamil $72 \mathrm{~kg}$, usia rata-rata 29,7 tahun, TFU ratarata 31,2 cm dan lingkar perut 93,3 dan rata-rata BB lahir 3195 gram.

Tabel 1.

Karakteristik Responden Primipara Berdasarkan BeratBadan, Usia, TFU, Lingkar Perut dan Berat Bayi Lahir

\begin{tabular}{lccccc}
\hline \multicolumn{1}{c}{ Primipara } & n & Minimal & Maksimal & Mean & SD \\
\hline BB Sebelum Hamil & 52 & 37 & 75 & 51,2 & 5,843 \\
BB Hamil & 51 & 44 & 90 & 60,6 & 6,627 \\
Usia & 52 & 19 & 37 & 26,7 & 4761 \\
TFU & 52 & 23 & 39 & 31,2 & 3.250 \\
Lingkar Perut & 52 & 74 & 120 & 94,2 & 9.607 \\
BB Lahir & 52 & 1800 & 4100 & 3157 & 469.2 \\
\hline
\end{tabular}

Gambaran taksiran berat janin berdasarkan metode pengukuran TBJ dan berat bayi lahir pada primipara dan multipara

Tabel 3 menunjukan hasil penelitian tentang taksiran berat janin pada primipara di peroleh hasil untuk TBJ metode Johnson Tohsch rata-rata 2969 gram, Johnson Sahrir 3114 gram, Niswander 2812 gram, Dares rata-rata 2614 gram, dan sederhana rata-rata 2953 gram, rata-rata BB lahir pada primipara 3157 gram. Sedangkan, tabel 4 menjelaskan hasil penelitian tentang taksiran berat janin pada primipara 


\section{Pengukuran Taksiran Berat Janin Saat Bayi Baru Lahir pada Primipara Lebih Akurat ... Martini Fairus, Martini Martini, Riyanto Riyanto \\ Jurnal Kesehatan Metro Sai Wawai. 12 (1) 2019. E-ISSN 2657-1390. P-ISSN19779-469X}

di peroleh hasil untuk TBJ metode Johnson Tohsach rata-rata 2961 gram, Johnson Syahrir 3101 gram, Niswander 2875 gram, Dare's rata-rata 2575 gram, dan sederhana rata-rata 2918 gram, rata-rata BB lahir pada multipara 3195 gram.

Tabel 2.

Karakteristik Responden Multipara Berdasarkan Berat Badan, Usia, TFU, Lingkar Perut dan Berat Bayi Lahir

\begin{tabular}{lccccc}
\hline Multipara & n & Minimal & Maksimal & Mean & SD \\
\hline BB Sebelum Hamil & 52 & 38 & 62,0 & 50,3 & 8.077 \\
BB Hamil & 52 & 45 & 72,0 & 59,3 & 9.077 \\
Usia & 52 & 20 & 40,0 & 29,7 & 5.622 \\
TFU & 52 & 24 & 38 & 31,2 & 2.999 \\
Lingkar Perut & 52 & 80 & 121,0 & 93,3 & 9.603 \\
BB Lahir & 52 & 2400 & 4100 & 3195 & 387.4 \\
\hline
\end{tabular}

Tabel 3.

Taksiran berat janin berdasarkan metode pengukuran tbj dan berat bayi lahir pada primipara

\begin{tabular}{|c|c|c|c|c|}
\hline Taksiran Berat Janin & Minimal & Maksimal & Mean & SD \\
\hline Johnson Tohsach & 1860 & 4185 & 2969,46 & 458.1 \\
\hline Johnson Syahrir & 1855 & 4020 & 3114,75 & 441.9 \\
\hline Niswander & 1836 & 3758 & 2812,82 & 380.2 \\
\hline Dare's & 1800 & 3400 & 2614,42 & 300.4 \\
\hline Sederhana & 2184 & 4446 & 2953,26 & 483.2 \\
\hline BB Lahir & 1800 & 4100 & 3157,21 & 469.2 \\
\hline
\end{tabular}

Tabel 4.

Taksiran Berat Janin Berdasarkan Metode Pengukuran dan Berat Bayi Lahir Pada Multipara

\begin{tabular}{lcccc}
\hline Taksiran Berat Janin & Minimum & Maximum & Mean & SD \\
\hline Johnson Tohsach & 1860 & 4030 & 2961,692 & 509.5 \\
Johnson Syahrir & 2295 & 3790 & 3101,231 & 370.3 \\
Niswander & 1956 & 3516 & 2785,058 & 392.7 \\
Dare's & 2500 & 3900 & 2577,115 & 492.6 \\
Sederhana & 2088 & 4235 & 2918,808 & 414.3 \\
BB Lahir & 2400 & 4100 & 3195,192 & 387.5 \\
\hline
\end{tabular}

\section{Hasil analisis bivariat}

Analisis bivariat bertujuan untuk melihat keeratan korelasi antara variabel metode pengukuran taksiran berat janin dan berat janin yang dilahirkan dan mengetahui arah hubungan dari dua variabel numerik yaitu, mengetahui hubungan metode pengukuran taksiran berat janin dan berat bayi yang dilahirkan mempunyai derajat yang kuat atau lemah, dan juga apakah kedua variabel tersebut berpola positif atau negatif. Tabel 5 menunjukkan hasil analisis keeratan hubungan antara beberapa metode taksiran berat janin dengan berat bayi lahir, diperoleh nilai $r=0,642$ dan nilai $p=0,0005$, artinya hubungan TBJ metode Dare's dengan berat lahir pada primipara terdapat korelasi yang kuat yatu $64,2 \%$, dikuti metode Johnson Tohsach dan Niswander dengan nilai r 64,1\%. Sedangkan, pada tabel 6 dapat diketahui nilai $\mathrm{r}=0,787$ dan nilai $\mathrm{p}=0,0005$, artinya hubungan TBJ metode Johnson Sahrir dengan berat badan Lahir pada ibu multipara menunjukkan korelasi yang kuat, yaitu sebesar 78,7\%, diikuti dengan Johnson Tohsach $(78,2 \%)$ dan Niswander $(76,5 \%)$. 


\section{Pembahasan}

\section{Taksiran berat janin dengan berat badan lahir pada primpara}

Salah satu cara pemantauan pertumbuhan dan kesejahteraan janin melalui pengukuran taksiran berat janin untuk mencegah gangguan pertumbuhan janin secara dini. Hasil penelitian menunjukan pengukuran taksiran berat janin metode Dar's memiliki nilai korelasi terkuat $(\mathrm{r}=0,642 ; \mathrm{p}=0,0005)$ terhadap berat bayi lahir pada ibu primipara dibandingan menggunakan empat metode lain. Metode Dare's menunjukkan korelasi yang kuat dan akurasi (64,2\%).

Tabel 5.

Korelasi TBJ dengan BB Lahir pada ibu Primipara

\begin{tabular}{lccc}
\hline Variabel & Pearson Corelation & BB Lahir & Sig \\
\hline Dare's & $.642^{* *}$ & $.642^{* * *}$ & 0.000 \\
Tohsach & $.641^{* *}$ & $.641^{* *}$ & 0.000 \\
Niswander & $.641^{* *}$ & $.641^{* *}$ & 0.000 \\
Sederhana & $.604^{* *}$ & $.604^{* *}$ & 0.000 \\
Johnson Syahrir & $.522^{* *}$ & $.522^{* *}$ & 0.000 \\
\hline
\end{tabular}

Tabel 6.

Korelasi TBJ dengan BB lahir pada ibu Multipara

\begin{tabular}{lccc}
\hline Variabel & Pearson Corelation & BB Lahir & Sig \\
\hline Johnson Syahrir & $.787^{* *}$ & $.787^{* *}$ & 0.000 \\
Tohsach & $.782^{* *}$ & $.782^{* *}$ & 0.000 \\
Niswander & $.765^{* *}$ & $.765^{* *}$ & 0.000 \\
Dares & $.711^{* *}$ & $.711^{* *}$ & 0.000 \\
Sederhana & $.580^{* *}$ & $.580^{* *}$ & 0.000 \\
\hline
\end{tabular}

Hasil penelitian pada primipara ini sesuai dengan hasil penelitian di Medan tentang perbandingan akurasi taksiran berat badan janin menurut formula Dare's dengan Johnson Tohsach. Hasil formula Dare's lebih akurat dibandingkan Johnson Tohsach. Kedua formula ini juga ditunjukkan lebih akurat dalam diagnostik janin dengan berat badan >3000 gram dan kurang akurat dalam diagnositk janin dengan berat badan <3000 gram (Sahputra, Pasaribu, \& Fahdhy, 2014).

Tahun 1990, Dare's et al. mengajukan suatu formula yang lebih sederhana untuk menghitung taksiran berat badan janin, yaitu perkalian antara Symfisis Fundal Height (SFH) dengan Abdominal Girth (AG). Dare's et al. mencobakan metode ini pada 498 pasien dan mendapatkan korelasi yang baik antara angka taksiran dengan berat janin sesungguhnya $(\mathrm{r}=0,742)$. Dalam studi saat ini, rumus Dare's sedikit lebih akurat dibandingkan dengan rumus Johnson. Hal ini dapat dijelaskan dengan kurangnya koreksi untuk obesitas pada model Dare's dan tingginya prevalensi wanita $>90 \mathrm{~kg}$ dalam populasi studinya. Studi lebih besar yang melibatkan pasien obese dibutuhkan untuk menguji hipotesis dari rumus Dare's untuk taksiran berat janin pada wanita (Dare, Ademowore, Ifaturoti, \& Nganwuchu, 1990).

Metode ini dianggap lebih mudah digunakan berbagai kalangan dan memiliki nilai bias yang minimal dibandingkan penggunaan tinggi symphysial-fundal. Dari penelitian Mohanty, Das dan Misra didapatkan bahwa metode abdominal girth memiliki nilai prediktif yang baik untuk bayi berat lahir rendah (Mohanty, Das, \& Mishra, 2000). Hendaknya Bidan dan tenaga kesehatan lainnya menggunakan metode Dar's

\section{Taksiran Berat Janin Dengan Berat Badan Lahir Pada Multipara}

Pengukuran taksiran berat janin untuk pemantauan pertumbuhan dan kesejahteraan janin, sehingga dapat dilakukan secara dini pencegahan gangguan pertumbuhan janin. Hasil penelitian menunjukan bahwa pengukuran taksiran berat janin terhadap berata badan lahir pada multipara dengan metode Johnson Syahrir korelasi yang kuat, artinya lebih akurat dibandingkan metode lain dengan 
akurasi sebesar 78,7\%. diikuti dengan Johnson Tohsach (78,2\%) dan Niswander (76,5\%). Berdasarkan hasil tersebut taksiran berat janin menurut Johnson Tohsach dan Niswander berada di posisi kedua dan ketiga dengan nilai korelasi yang kuat baik pada primipara dan multipara.

Hasil penelitian yang diperoleh pada perkiraan taksiran berat janin pada ibu primipara dan multipara terdapat dua metode pengukuran yang berbeda yaitu Dare's pada primipara dan pada multipara Johnson Syahrir. Metode taksiran berat janin ibu primipara dan multipara pada posisi kedua dan ketiga adalah Johnson Tohsach dan Niswander. Hal ini dimungkinkan karena terdapat berbagai variasi penelitian terkait karakteristik responden.

Berbagai confounding factor seperti bias subjek dan bias pengukuran dapat terjadi. Dalam penelitian ini, berat badan ibu hamil tidak di lakukan analisis yang kemungkinan dapat menjadi terjadinya over estimasi atau sebaliknya. Walaupun begitu, penelitian- penelitian ini dan sebelumnya tetap menunjukkan formula Dare's lebih akurat dibandingkan Johnson Tohsach. Sehingga, taksiran berat janin menggunakan formula Dare's lebih akurat dibandingkan Johnson Tohsach pada primipara.

Formula Dare's dan Johnson Tohsach merupakan dua formula yang juga lebih akurat dalam diagnostik janin dengan berat badan $>3000$ gram dan kurang akurat dalam diagnositk janin dengan berat badan <3000 gram. Teori Pengukuran abdominal girth yang memberikan indikasi kasar untuk pertumbuhan janin dalam meter. Lingkar perut meningkat dengan ketebalan sekitar 2,54 cm (1 inch) perminggu melampaui 30 minggu dan pada saat aterm sekitar 95-100 cm (38-40 inch). Biasanya lingkar perut meningkat terus sampai dengan penyelesaian 38 minggu dan tetap stabil sesuai dengan panjang. Setelah aterm, jika kehamilan terus berlangsung, lingkar perut secara bertahap akan berkurang. Sehingga, kemungkinan hal inilah yang menyebabkan formula Dare's kurang tepat untuk digunakan pada ibu multipara (Shivakumar, 2001).

Ada beberapa rumus yang menggunakan pengukuran tinggi fundus uteri sebagai variabel utama untuk menduga berat badan lahir, dan pada penelitian ini diteliti validasinya untuk populasi di Lampung Tengah . Dalam penelitian ini didapatkan hasil bahwa rumus yang ditemukan para peneliti Barat ternyata kurang sesuai untuk mengestimasi berat badan lahir (rumus Niswander, Johnson, dan SFH) untuk populasi di Indonesia. Hal ini dimungkinkan karena adanya perbedaan ras. Euans, dkk, 1995 dalam penelitiannya menyatakan bahwa pengukuran tinggi fundus uteri dapat menggantikan pengukuran ultrasonografi, namun pengukuran ini dipengaruhi oleh ras (Euans, Connor \& Hahn, 1995).

Beberapa penyebab ketidaksesuaian taksiran berat janin dengan berat bayi lahir bisa disebabkan karena posisi ibu yang tidak tepat saat dilakukan pengukuran tinggi fundus uteri, tidak dilakukan pengosongan kandung kemih sebelum pemeriksaan tinggi fundus uteri, hal ini bisa disebabkan karena pemeriksa terburu-buru melakukan pengukuran fundus uteri pada saat kandung kemih masih terisi urine. Selanjutnya bisa juga dikarenakan pada saat ketuban sudah pecah tidak di tambahkan $10 \%$ seharusnya ditambah $10 \%$ dan tinggi fundus diukur dalam sentimeter. Selain itu, perbedaan metode taksiran berat janin pada primipara dan multipara dimungkinkan karena peneliti tidak membandingkan perbedaan antara primpipara, multipara dan grandemultipara. Begitu pula dengan usia ibu, apakah terdapat perbedaan antra ibu usia antara 20-35 tahun dengan usia >35 tahun. Diharapkan pada penelitian selanjutnya beberapa faktor yang menyebabkan terjadinya bias pada penelitian ini dapat dianalisis lebih lanjut.

\section{Simpulan dan Saran}

Pengukuran taksiran berat janin dari lima metode pada primipara menunjukkan hasil korelasi yang paling kuat dalam menaksir berat bayi lahir adalah metode Dare's (64\%) dan pada multipara korelasi metode pengukuran taksiran berat janin terhadap berat bayi baru lahir yang paling kuat adalah metode Johnson Tohsach (78,2\%). Hendaknya Bidan dan tenaga kesehatan lain dalam memberikan asuhan antenatal care, khususnya pengukuran estimasi berat janin dalam rahim pada primipara 


\section{Pengukuran Taksiran Berat Janin Saat Bayi Baru Lahir pada Primipara Lebih Akurat ... Martini Fairus, Martini Martini, Riyanto Riyanto

menggunakan metode Dare's. Sedangkan, pengukuran estimasi taksiran berat janin dalam rahim pada multipara menggunakan metode Johnson Tohsach.

\section{Referensi}

Dare, F., Ademowore, A., Ifaturoti, O. \& Nganwuchu, A. (1990). The value of symphysio-fundal height/abdominal girth measurements in predicting fetal weight . Int J Gynaecol Obstet, 243-8.

Euans, D., Connor, P., \& Hahn RG, d. (1995). A comparison of manual and ultrasound measurements of fundal height233-6. J Fam Pract, 233-6.

Fairus, M., \& Widiyanti, S. (2005). Faktor-faktor yang berhubungan dengan kejadian intra uteri fetal death di Rumah Sakit Kota Metro, Bandar Lampung. Perpustakaan Politeknik Kesehatan Tanjungkarang.

Mohanty , C., Das, B. K., \& Mishra, O. P. (2000). Parturient Abdominal Circumference as a Predictor of Low Birthweight. Journal of Tropical Pediatrics Banaras Hindu University. J Trop Pediatr, 46(6), 363-4. doi:doi: $10.1093 /$ tropej/46.6.363.

Sahputra, E. E., Pasaribu, P. H., \& Fahdhy, M. (2014). Perbandingan akurasi taksiran berat badan janin menurut formula dare's dengan johnson tausack. Abstraks, p.1-9. Retrieved from http://repository.usu.ac.id/bitstream/

Shivakumar, H. (2001). Symphysio fundal height measurement during labour for estimation of foetal weight and correlation with birth weight No 4. J Obstet and gynecol of India, 51, 118- 122.

Sopiyudin. (2011). Besar sampel \& cara pengambilan sampel dalam penelitian kedokteran dan kesehatan. Salemba Medika.

Varney, H., Kriebs, J. M., \& Gegor, C. L. (2008). Buku Ajar Asuhan kebidanan. Vol 1 ed 4. Jakarta: Buku Kedokteran EGC 